\title{
The Anyang Xibeigang Shang royal tombs revisited: a social archaeological approach
}

Koji Mizoguchi ${ }^{1, *} \&$ Junko Uchida $^{2}$

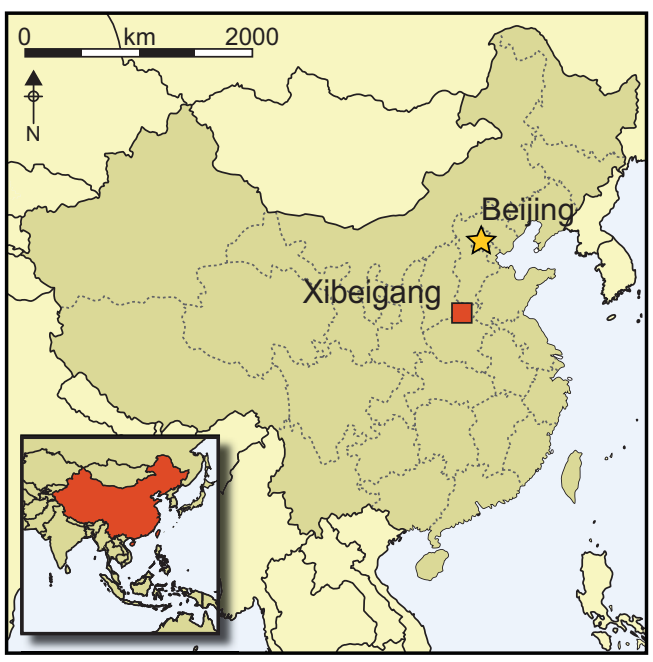

The Shang Dynasty has attracted much archaeological research, particularly the renowned 'royal tombs' of the Xibeigang cemetery at Anyang Yinxu, the last Shang capital. Understanding of the social strategies informing Shang mortuary practices is, however, very limited. A new reconstruction of the detailed chronology of the cemetery is presented here, allowing social theory to be applied, and reveals the strategic social decisions behind the placement of the tombs in relation to each other. The results of this analysis are important not only for the reconstruction of the social structure and organisation of the late Shang dynasty, but also for understanding the relationship between mortuary practices and the functioning of early states in other regions.

Keywords: China, Anyang, Shang dynasty, Xibeigang cemetery, mortuary archaeology

\section{Introduction}

The Shang (商) 'Dynasty', as an example of an 'early civilisation', has attracted significant international research (e.g. Chang 1980; Trigger 2003; Yoffee 2005). From 1935-1937, the Institute of History and Philology of Academia Sinica excavated the 'royal tombs' at the Xibeigang (the official excavation reports describe it as $H_{s i}$-Pei-Kang, abbreviated as HPKM) 西北岡 cemetery of Anyang-Yinxu 安陽殷墟 (Figure 1). Although heavily robbed, the tombs yielded invaluable evidence that has allowed archaeologists to investigate

1 Faculty of Social \& Cultural Studies, Kyushu University, 744 Moto'oka, Nishi Ward, Fukuoka 819-0395, Japan

2 Institute of History and Philology, Academia Sinica, No. 130, Section 2, Academia Road, Nangang District, Taipei, Taiwan

* Author for correspondence (Email: mizog@scs.kyushu-u.ac.jp)

(C) Antiquity Publications Ltd, 2018. This is an Open Access article, distributed under the terms of the Creative Commons Attribution-NonCommercial-NoDerivatives licence (http://creativecommons.org/licenses/ by-ncnd/4.0/), which permits non-commercial re-use, distribution and reproduction in any medium, provided the original work is unaltered and is properly cited. The written permission of Cambridge University Press must be obtained for commercial re-use or in order to create a derivative work. 

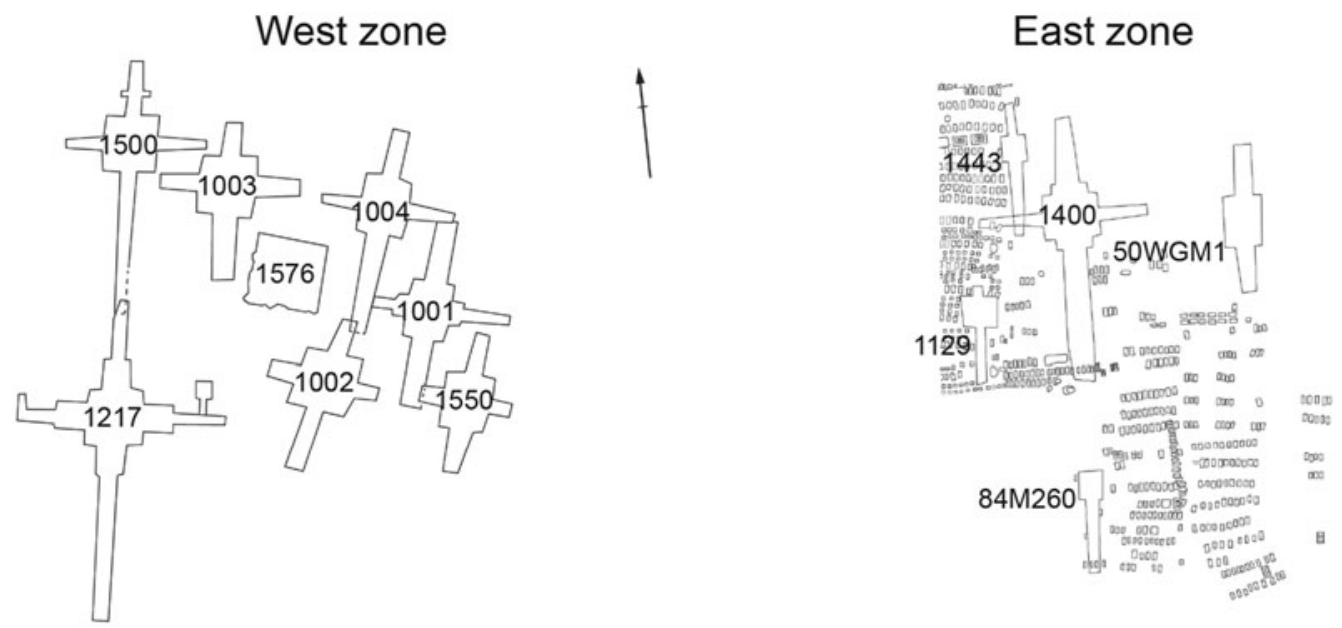

Figure 1. General plan of the Xibeigang cemetery, Anyang Yinxu (after Liang \& Gao 1962, 1965, 1967, 1968, 1970, 1974, 1976, 1996; Anyang Archaeological Team IA CASS 1987; IA CASS 1994).

the successive late Shang kings, their genealogical relationships and the ritual-based system of governance (e.g. Chang 1977: 282-85, 1980). Comparison of the outcomes of the investigation of the royal tombs with that of the study of so-called 'oracle bones' bearing scripts written in primitive Chinese characters has also illuminated aspects of the workings of an early state (e.g. Chang 1977: 282-85, 1980; Barnes 2015).

By examining spatio-temporal evidence at cemetery sites, Mizoguchi (e.g. 1993, 2005, 2013, 2014, 2015) has developed a methodological framework for reconstructing the strategies adopted by those who planned and performed ancient mortuary practices. Through this perspective, Mizoguchi noted complex spatial relationships between the Xibeigang tombs, which strongly suggested the careful strategic placement of tombs in relation to pre-existing tombs, with the intention of making socio-political statements. Meanwhile, Uchida has studied the 'Gu-si' 骨柶 ritual spatulas made from animal bone, excavated from the Xibeigang tombs. By correlating their stylistic changes over time to that of other artefacts from the tombs, it has become possible to date the construction of the respective tombs accurately and to reconstruct the formation process of the Xibeigang cemetery (Namba 1990, 1995a \& b; see also the online supplementary material (OSM)).

By combining these approaches, it is possible to investigate the socio-symbolic strategies adopted by those who constructed the tombs and designed and conducted funeral ceremonies, and to reconstruct the meanings, such as respect paid to the previously buried 'ancestors' in the same cemetery, designed to be generated through funeral ceremonies. It is hoped that the results will illuminate how authority and power were negotiated and reproduced through the mortuary practice of the Shang ruling figures and their factions (cf. Brumfiel \& Fox 2003).

(C) Antiquity Publications Ltd, 2018 

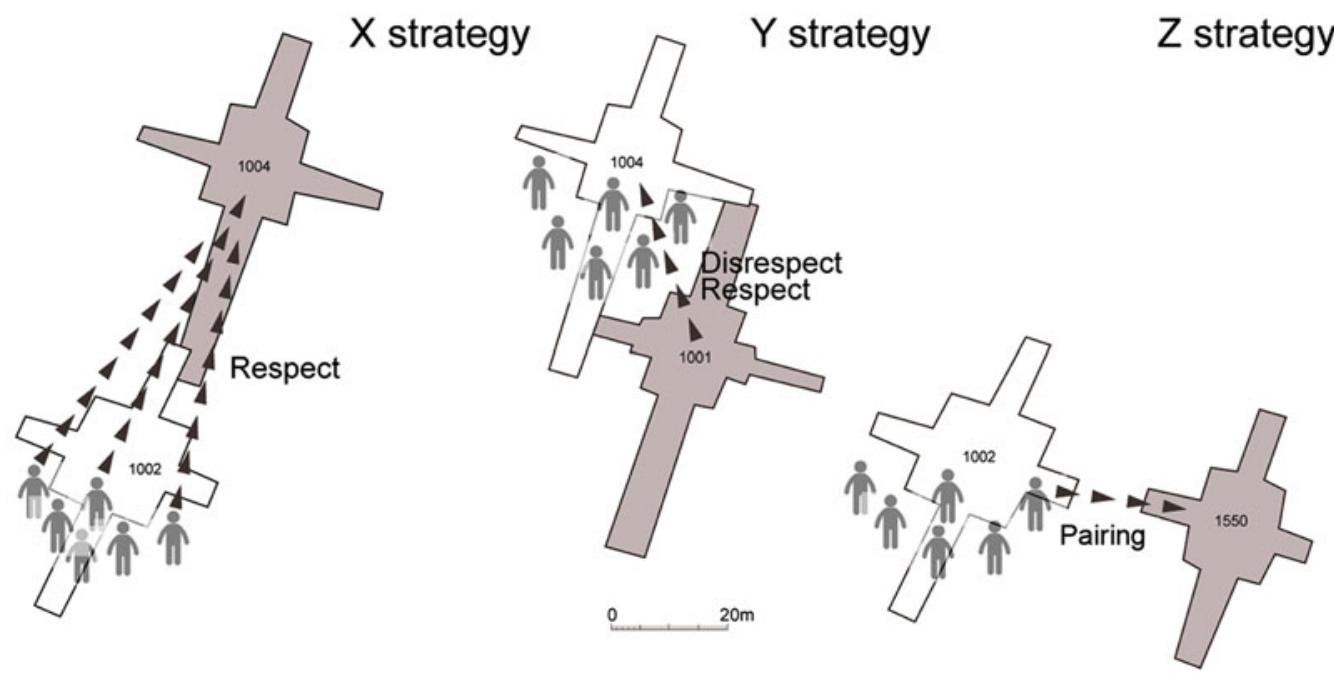

Z strategy

Figure 2. Three mortuary strategies demonstrating manipulation in the positioning of funeral participants and the direction(s) to which their gazes were directed. Arrows indicate the direction that participants were orientated.

\section{Material and methods}

This investigation of late Shang royal tombs of the Xibeigang cemetery takes a socialinterpretative archaeological perspective. Here, social-interpretative archaeology centres upon the reconstructive investigation of the intention and strategy adopted by those who conducted certain social practices (cf. Tilley 1994). Such intentions and strategies are 'chosen' from a repository of memories or customs that are preserved mostly in the form of 'practical consciousness' (i.e. internalised or embodied memories from which we decide how to handle certain social settings; see Giddens 1984: 41-45).

To identify the archaeological evidence for such practical consciousness, we must situate the available evidence in the flow of time. The material traces of those past funerary occasions would have helped to preserve internalised memories, would have been referred to and would have been symbolically used in various manners and for various purposes in the practice (e.g. Mizoguchi 1993; Parker Pearson 1999: 193-97).

At the Xibeigang cemetery, a 'royal tomb' is comprised of a rectangular main burial chamber with a sloping ramp attached to each of the four sides (Figures $1 \& 2$ ). Some tombs were built immediately in front of the designated 'front' of a pre-existing tomb (the 'front' being marked by the southern ramp in each case $($ strategy $X)$. Those who participated in the funeral would have faced towards a specific pre-existing tomb, thereby effectively paying respect to both the person buried in that tomb and the person being buried (Figure 2). Interestingly, other tombs were constructed immediately behind the 'rear' of a pre-existing tomb. In those cases, the mourners turned their backs on the deceased, literally showing disrespect to the occupant (strategy Y), or putting themselves in the position of being respected by the deceased of the pre-existing tomb (strategy Y') (Figure 2). Y and Y' strategies have vastly different intentions behind them and we must, where possible, differentiate them from one another. In most cases, however, it may be difficult to specify which is which. 
There were also tombs located as if they were pairing with one another, although there must have been a gap between their construction. Here, it can be inferred that those who conducted the funeral at the later tomb intended to portray the person that they were burying as 'equal' to the person buried in the earlier grave (strategy Z) (Figure 2). Such strategic placement of the later tombs was made possible by the probable presence of an ancestral shrine. An ancestral shrine structure (F1) was excavated on the tomb of Fu-Hao 婦好, and is assumed to be the 'shrine of Mother Xin'-the posthumous name of Fu-Hao, recorded in oracle bone scripts (IA CASS 1980). Markers, such as low earthen platforms, probably also indicated the location of the main burial pit and the four ramps of the pre-existing tombs. Furthermore, as the edges of at least one of the ramps of a newly built tomb often overlap slightly with those of a pre-existing tomb (Figures $1 \& 2$ ), it is probable that the strategies were very carefully designed and pre-planned. It is, however, virtually impossible to prove whether it was the kings themselves who designed or planned such strategies prior to their death, or if it was those who conducted the funerary rituals. Through examination of the available evidence, we will attempt to verify this inferential hypothesis regarding the importance of ancestors and the cultic reproduction of kingly authority (Keightley 1999).

\section{Analysis: reconstructing the chronology of the Xibeigang cemetery}

Previous attempts to reconstruct the chronology of the Xibeigang royal tombs have relied mainly on the examination of partial overlaps between some of the tombs (e.g. Li 1959; Kane 1975; Anonymous 1977; Chang 1980: 117-19; Yang 1981, 1991). The tombs were heavily robbed and most of the datable artefacts (such as bronze items) that could be attributed to specific phases of the typo-chronological sequence were lost (Liang \& Gao 1962, 1965, 1967, 1968, 1970, 1974, 1976, 1996; cf. Namba 1990; IA CASS 1994). Such overlaps, however, are present only between tombs 1001 and 1550 (the latter was constructed later than the former), between 1001, 1004 and 1002 (constructed in that order), and between 1500 and 1217 (the latter constructed later than the former) (Figure 1). Neither 1003 nor 1400 display such overlapping (Figure 1). Thus, the previous interpretations failed to locate tombs 1003 and 1400 convincingly in the Xibeigang sequence (see Table 1).

Since the 1950s, a relative chronology has been developed using Anyang pottery vessels, and is informed by the classification of bronzes and other items. The result of this is the four-phase Anyang Yinxu chronology (IA CASS 1994). Yinxu tomb 5 (the tomb of FuHao, a wife of the twenty-second Shang ruler Wu-Ding) in the palace complex at Xiaotun 小屯 Village had not been robbed, and yielded a grave assemblage typical of the second phase of the chronological scheme (IA CASS 1980). Amongst the large tombs of the Xibeigang cemetery, 1443 and 50WGM1 are thought to pre-date the first phase, and, importantly, are probably contemporaneous with Huanbei Shangcheng 洹北商城, located immediately north-east of Yinxu, and dating from the Middle Shang period (Tang 1999). Tombs 1550, 1400 and 1004 are contemporaneous with the Fu-Hao tomb, and hence date to the second phase. These are the only tombs that can be convincingly situated in the Yinxu chronological system.

Study of the ritual bone 'Gu-si' spatulas decorated with carved symbolic motifs has, however, enabled Uchida to construct a chronological system that allows the temporal (C) Antiquity Publications Ltd, 2018 
Table 1. Comparing the dates (Li, Yang \& Yang and Mizoguchi \& Uchida) of the royal tombs of Xibeigang.

\begin{tabular}{lcccc}
\hline Tomb number & Li (1959) & $\begin{array}{c}\text { Yang \& Yang } \\
(1977)\end{array}$ & $\begin{array}{c}\text { Mizoguchi \& } \\
\text { Uchida }\end{array}$ & $\begin{array}{c}\text { Yinxu } \\
\text { chronology** }\end{array}$ \\
\hline 1129 & - & - & $?$ & $\begin{array}{c}\text { Huan-bei } \\
\text { Shang-cheng phase } \\
\text { Huan-bei }\end{array}$ \\
1443 & - & - & -2 & Shang-cheng phase \\
50 WGM1 & - & - & -1 & I \\
1001 & 1 & $1^{*}$ & 1 & I \\
1550 & 2 & 2 & 2 & II \\
1400 & - & 3 & 3 & II \\
1004 & 3 & 8 & 5 & III \\
1003 & 5 & 5 & 6 & III \\
1002 & 4 & 6 & 7 & III/IV \\
1500 & 6 & 7 & 8 & III?IV \\
1217 & 7 & & & \\
\hline
\end{tabular}

* Yang and Yang (1977) believe this to be the tomb of Wu-Ding.

** See the OSM and Yang (1991).

positions of all the royal tombs at the Xibeigang cemetery to be determined. Steady diachronic change can be recognised in the following attributes of these spatulas (Figure 3) (Namba 1990, 1995a \& b; see also the OSM):

1) Morphology: the earliest specimens preserve the original shape of the cattle rib and leg bones from which they are formed. They are large in size and curved in cross section. Over time they become rectangular and plate-like, and gradually smaller, straighter in cross section, with concave long sides.

2) Carving: the initially large number of design units comprising the whole design gradually decreases. Carving is initially in relief but gradually changes to flatter modes with incised motifs (Figure 3).

3) Design: motifs fall into two main traditions (see Figure $S 1$ in the OSM), each of which shows a distinct process of economisation and simplification in terms of the carving technique and design employed.

4) The original bone crest tends to be left unworked in the earlier specimens but is increasingly worked over time; the top is flattened and certain design motifs are incised in it (Figure 3a).

These gradual and continuous changes allow ritual bone spatulas to be classified into well-defined types. Examination of each specimen excavated from the different tombs has hence enabled us to determine the relative position of each tomb in the overall chronology of Xibeigang. This analysis shows that tomb 1001 is the oldest in the sequence (Figure $3 \mathrm{~b}$ ). The spatulas from this tomb include large painted specimens, with a wide range of motifs carved in relief. The western ramp of tomb 1550 cuts the southern ramp of tomb 1001 (Figure 1), thus suggesting that 1001 pre-dates 1550 . The spatulas from tomb 

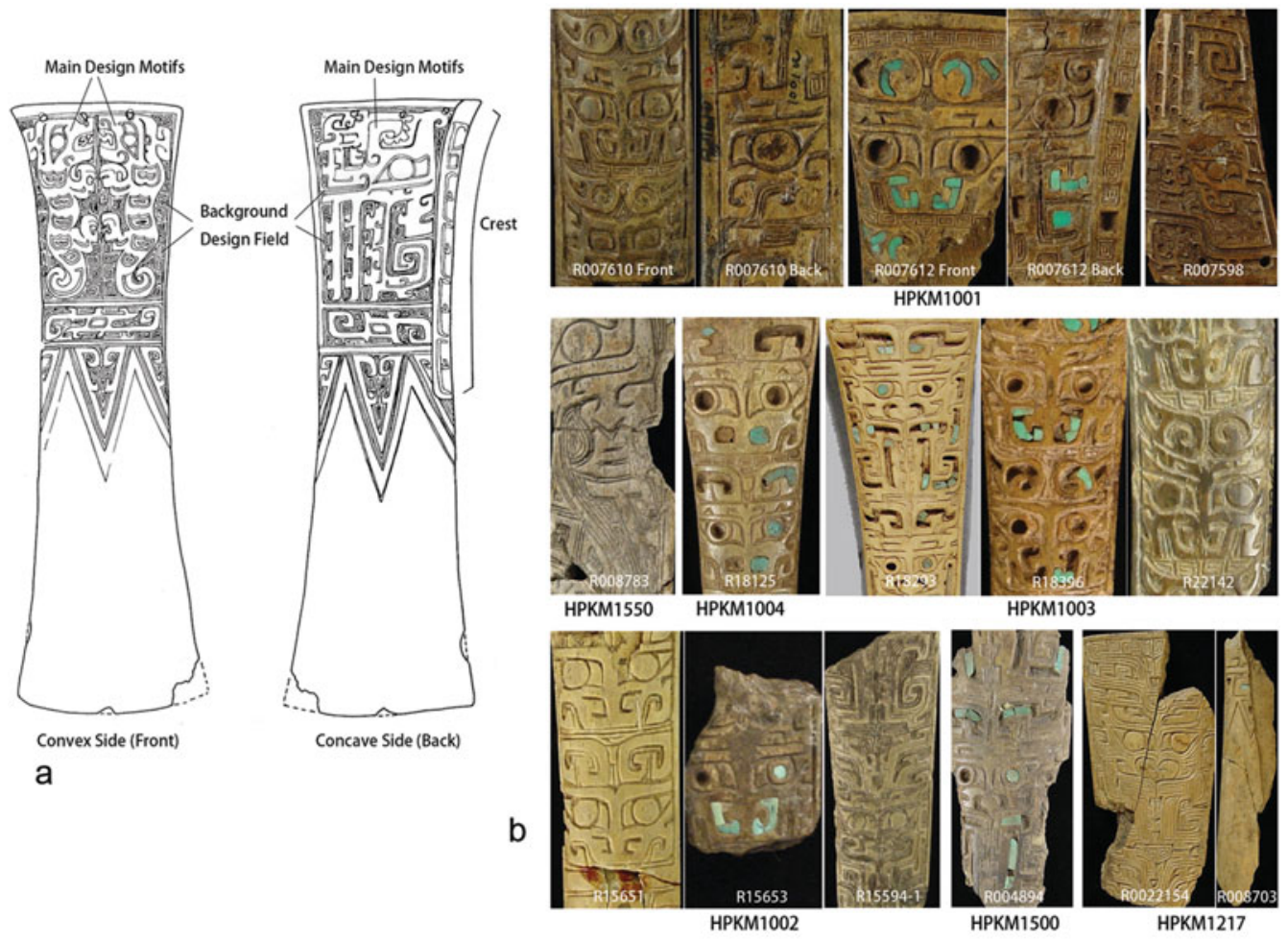

Figure 3. 'Gu-si' 骨柶 and its typo-chronological sequence. A) Parts and names used in the text (213mm in length, and $65 \mathrm{~mm}$ in width; after Umehara 1940: fig. 82); B) specimens from respective tombs, presented in chronological order (Institute of History and Philology, Academia Sinica).

1550 still include large painted specimens, but the design motifs are in shallower relief (Figure 3b).

The eastern and southern ramps of tomb 1004 cut the northern and western ramps (respectively) of tomb 1001 (Figure 1). Large painted spatulas are absent from tomb 1004, and the design motifs of the spatulas from this tomb are less sophisticated and flatter in their execution than that of tomb 1550 (Figure 3b). Tomb 1004 was therefore probably constructed after tomb 1550.

Tomb 1003 was probably constructed after tomb 1004, as the spatulas are flatter in cross section, the main design elements are in shallower relief and the background to the design fields is left unfilled (Figure 3b). These changes imply a further simplification of design.

Tomb 1002 was probably constructed after tomb 1003, as the main motif of the background to the design fields (spirals) begins to be replaced by parallel lines (Figure 3b). In tomb 1500 the spiral motifs have been completely replaced by sets of parallel lines, suggesting that it was constructed after 1002 .

The northern ramp of tomb 1217 overlaps the southern ramp of tomb 1500, and the spatulas from this tomb have incised line designs with no relief elements (Figure $3 \mathrm{~b}$ ). Combined, this evidence suggests that tomb 1217 is later than both tombs 1002 and 1500,

(C) Antiquity Publications Ltd, 2018 
placing it at the end of the whole cemetery sequence (with the exception of unfinished tomb 1576).

This investigation allows us to reconstruct the chronology of the Xibeigang royal tombs as follows:

$$
1001 \rightarrow 1550 \rightarrow 1004 \rightarrow 1003 \rightarrow 1002 \rightarrow 1500 \rightarrow 1217
$$

The available evidence suggests that tomb 1400 (Figure 1) was built between the construction of tombs 1550 and 1004. The bronze vessels excavated from tomb 1400 date to the Yinxu II phase (Namba 1990, 1995a \& b; IA CASS 1994; see also the OSM), whereas the vessels from tomb 1001 date to the late Yinxu I phase and the vessels from tomb 1550 date to the Yinxu II phase. Those from tomb 1400, however, display traits chronologically later than those from tomb 1550 (see also the OSM). This further indicates that tomb 1400 was constructed after tomb 1550. It should also be added that a bronze halberd and a Gu vessel from tomb 1004 date from the late Yinxu II phase (Namba 1990, 1995a \& b; see also the OSM).

These observations point to the following sequence of tomb construction:

$$
1001 \rightarrow 1550 \rightarrow 1400 \rightarrow 1004 \rightarrow 1003 \rightarrow 1002 \rightarrow 1500 \rightarrow 1217
$$

Tombs 1129, 1443 and 50WGM1 (which may represent the royal tombs of three Middle Shang kings), located in the eastern half of the cemetery, have only two ramps attached to the north and south sides of the main burial pit (Figure 1). Tomb 1129 did not yield any datable artefacts. Tomb 1443 yielded jade artefacts dating to the Middle Shang period, while tomb 50WGM1 yielded bronze items dating to the Yinxu I phase. This evidence suggests that these tombs mark the beginning of the use of this location as a cemetery for high-ranking individuals. The unfinished nature of tomb 1576 and its location in the middle of a cluster of other royal tombs suggests that it marks the end of the use of the location as a royal cemetery. These inferences thus create the sequence

$$
\begin{aligned}
1443 & \rightarrow 50 \text { WGM } 1 \rightarrow 1001 \rightarrow 1550 \rightarrow 1400 \rightarrow 1004 \rightarrow 1003 \rightarrow 1002 \\
& \rightarrow 1500 \rightarrow 1217 \rightarrow 1576
\end{aligned}
$$

Table 1 summarises the analysis and argument, and compares Li's (1959) and Yang and Yang's (1977) sequences with ours. The positions of the respective tombs are also compared with the four phases of the Yinxu chronological scheme (see also the OSM).

\section{Interpretation}

\section{A. Social strategies and their implications}

The phasing of the Xibeigang royal tombs (Figure 1) followed a relatively complex pattern (Figure 4), suggesting that social messages were expressed by locating the burial of an individual in a certain spatial relationship to those who had been buried previously (cf. Mizoguchi 2005). Such 'constructed relationships' include the previously mentioned X (respectful), Y (disrespectful or being respected) and Z (pairing) strategies. Additionally, 
Koji Mizoguchi \& Junko Uchida
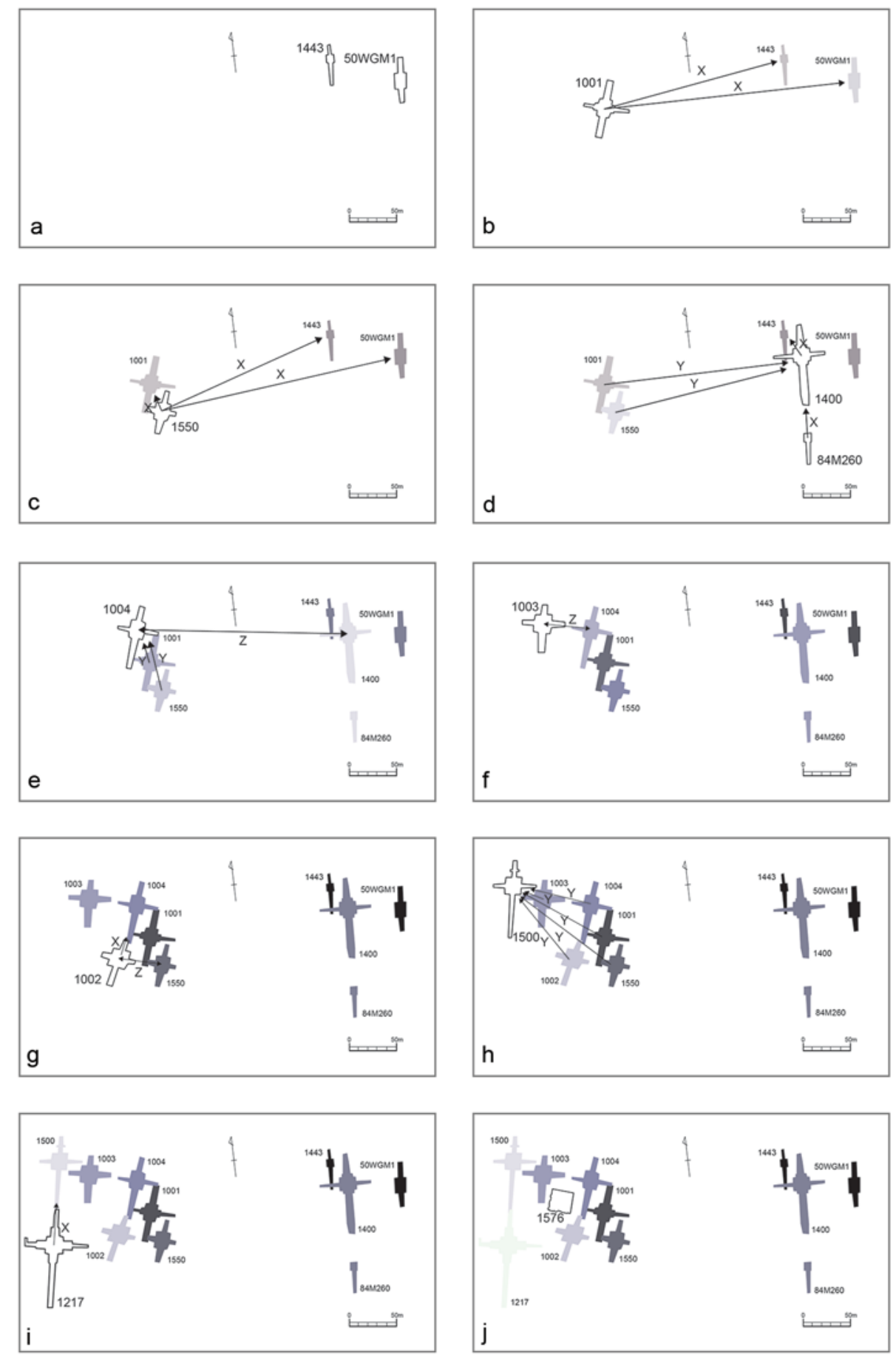

Figure 4. Chronology of the Xibeigang cemetery. $X, Y, Z$ and respective arrows: mortuary strategies and intended references (see too, Figure 2).

(C) Antiquity Publications Ltd, 2018 
competition between groups or lineages can be recognised. Although previous studies of the oracle bone scripts have attempted to define these 'groups', it is sufficient here to identify them as factions based upon kin affiliations, including both genuine and fictive (see Chang 1980: 158-89; for the concept of 'factions', see Brumfiel \& Fox 2003). The current analysis focuses on the strategies adopted by such faction(s) in each funerary event throughout the sequence.

When tombs 1001 and 1550 in the western zone and tomb 1400 in the eastern zone were built, tombs 1443 and 50WGM1 were already extant (Figure 4a-d). As tomb 1129 (see Figure 1) did not yield any datable artefacts, it is omitted from the following study. It is important to note that tombs 1001,1550 and 1400 were placed slightly to the south of those two pre-existing tombs (Figures $1 \& 4 \mathrm{~b}-\mathrm{d}$ ). Each of the three tombs had their main entrance on the southern side, suggesting that 1001, 1550 and 1400 were built in a position that naturally caused the mourners to $\mathrm{X}$ to pay respect to the deceased of 1443 and 50WGM1. In the case of 1550, the mourners were also made to pay respect to the deceased of 1001 (Figure 4c). This strategy is particularly clear in the relationship between tombs 1443 and 1400 (Figures $1 \& 4 \mathrm{~d}$ ): a participant at the funeral of 1400 would have had tomb 1443 - probably represented by an ancestral shrine or a very low platform — within view. This suggests that the royal cemetery was initially located here with the intention of paying respect to, and effectively emphasising the deceased's connection with, ancestors buried in tombs 1443 and 50WGM1.

It should also be noted that tomb 1400 in the eastern zone was positioned so as to be paid respect by those buried in 1001 and 1550 - an example of strategy Y (Figure 4d). Tomb 84M260 was situated immediately in front of the southern ramp of 1400, thereby compelling the mourners to pay respect to the individual buried within 1400; this is an example of strategy X (Figure 4d).

Tomb 1004 was constructed to the north-west of 1001, as if deliberately placing the deceased so as to be paid respect by the occupants of 1001 and 1550-an example of strategy Y (Figure 4e). Tomb 1004 was also placed with the clear intention of displaying the genealogical proximity of its occupant to 1001 . The strategic intention of the mourners of tomb 1004 was, therefore, to situate the occupant as the genealogical successor to that of 1001 , and simultaneously to demonstrate the higher social status/position of the individual buried in 1004 (Figure 4e). Interestingly, the main burial pit of 1004 was situated at almost the same latitudinal position as 1400 (Figure 4e). This suggests that the mourners who constructed tomb 1004 tried to locate the deceased in an equivalent pairing position to that of 1400-an example of strategy Z.

As suggested, tomb 1003 was constructed after 1004 and before 1002 (Figures 1 \& 4f). It can be concluded that tombs 1003, 1500 and 1217 formed a distinct subcluster (Figure 1), not only because of their mutual proximity, but also through sharing an identical longitudinal axis (Figure 1). Tomb 1003 was similarly placed as if designed to be paired (strategy Z) with 1004 (Figure 4f). Tombs 1001, 1550, 1004 and 1002 formed a cluster, but 1003 was not built to be a part of it (Figure 1). These observations suggest that the mourners of 1003 intended to position the deceased as the equal of, and successor to, the occupant of 1004, although the deceased of 1003 belonged to a different lineage. 
The construction of tomb 1002 followed that of 1003, which was further followed by 1500 (Figure 4g-h). What makes 1002 particularly remarkable is that it was situated as if the occupant was to be paired with 1550 (strategy Z); a considerable length of time must have passed between the construction of 1550 and 1002 (Figures $1 \& 4 \mathrm{~g}$ ). In their longitudinal axes and size of their main burial pits, the tombs were identical and their front ramps were much shorter than those of 1001 and 1004 . They also were much shorter than those of 1500 and 1217 (Figure 1). Regardless, the mourners of 1002 did not try to 'outdo' the funeral of 1003; they showed their respect to (strategy X), and the close genealogical relationship with, the individual buried in 1004 (Figure 4g).

The chronology of the ritual bone spatulas confirms that tomb 1500 post-dates tomb 1002 (Figure 4h). Tomb 1500 was given the northernmost position of the entire Xibeigang cemetery, effectively placing its deceased to be respected by all of those buried in the preceding graves - the execution of strategy $\mathrm{Y}$ on a grand scale (Figure 4h).

Tomb 1217 post-dates tomb 1500 (Figure 4i), and was also situated so as to express its respect to (strategy $\mathrm{X}$ ), and genealogical succession from, 1500. The northern ramp of 1217 also overlaps the southern ramp of 1500 (Figure 4i). Interestingly, however, 1217 had longer ramps and its burial pit was of similar shape to those of 1001 and 1400, the two oldest royal tombs of Xibeigang (Figure 1). This suggests that the mourners of 1217 intended to portray the deceased not only as having a close genealogical tie with 1500 , but also as reviving the old tradition by emulating the shape of the main burial pits of 1001 and 1400 . This may accrue more significance if we consider that tomb 1576, which post-dates tomb 1217 (Figure 4j), was abandoned, unfinished. It is tempting to argue that the mourners of the occupant of 1217 felt that continuation of the lineage (or lineages) of the elite was in danger. Accordingly, they tried to revitalise their faction(s) and their genealogical continuity by emulating or reviving the manner and style in which the founders of the lineage, or lineages (i.e. the ancestors buried in 1001 and 1400), were buried. Despite their highly symbolic effort, the lineage (or lineages) did indeed come to an end.

\section{B. Comparing the outcome to historical sources}

The dynastic genealogy of the late Shang kings ruling from the capital at Yin 殷 (Anyang) is documented in the well-known Shiji 史記 and Zhuishü Jinián 竹書紀年 (the Bamboo annals). It is thought that Wu-Ding (武丁) moved the capital to Yinxu at around 1250 BC (Xia Shang Zhou Chronology Project Team 2000). Ten successive kings then ruled the domain before the last Shang king, Di-Xin (帝辛), was killed and Shang rule was ended by the Zhou Dynasty in 1046 BC (Xia Shang Zhou Chronology Project Team 2000). The kings documented in Shiji and in the oracle bone scripts coincide fairly well, although some of the reigns recorded in Shiji (written some 800 years later) are too long to be feasible. The Shiji entries that coincide with descriptions in the oracle bone scripts, however, can be trusted. Importantly, King Lin-Xin’s (床辛) enthronement is in doubt because his name does not appear in the oracle bone records, although the Shiji includes him. If Lin-Xin is removed from the dynastic genealogy, the number of the royal tombs and that of the kings recorded in these documents match perfectly (Figure 5):

(C) Antiquity Publications Ltd, 2018 


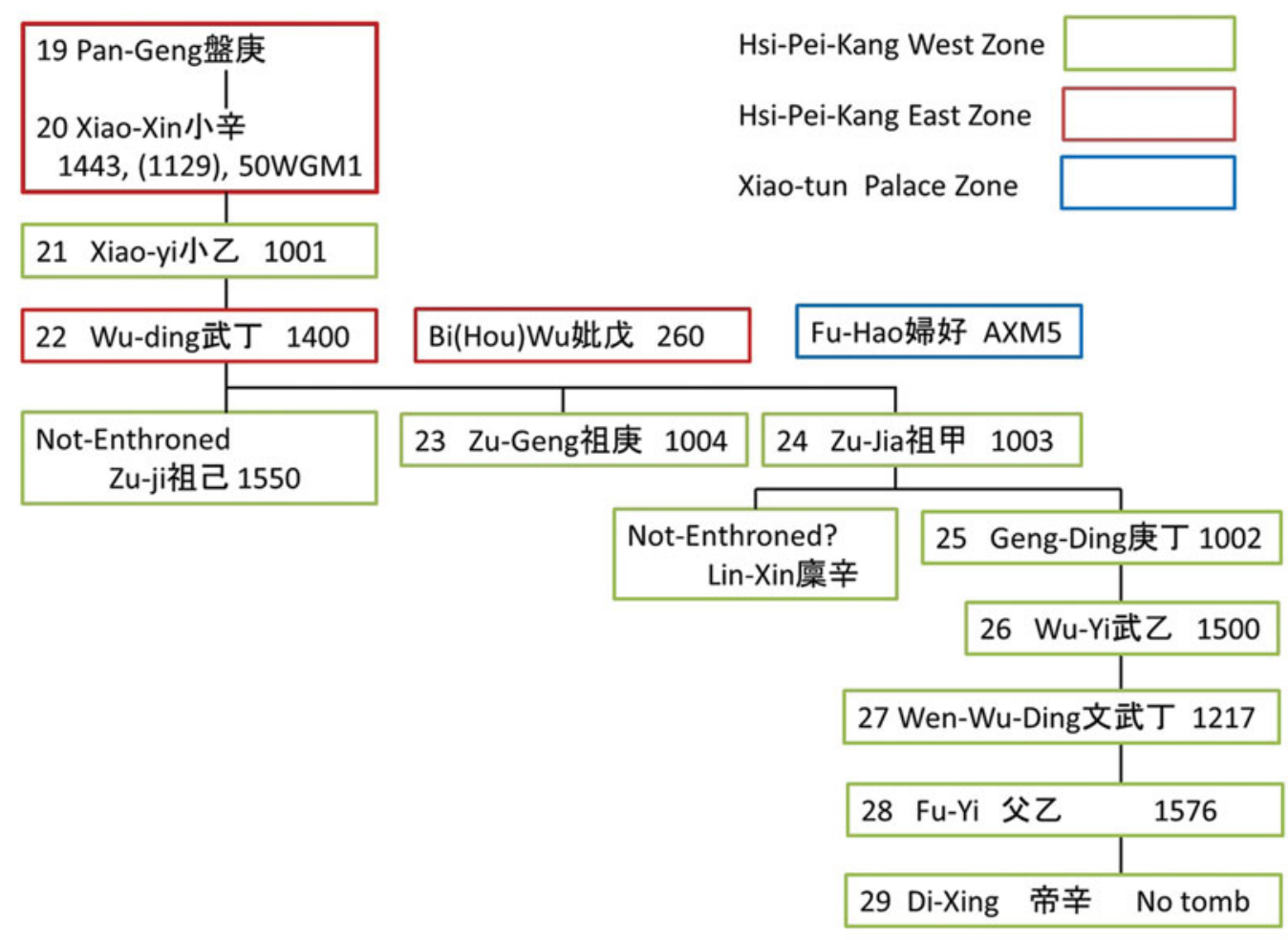

Figure 5. Late Shang 'kings', their genealogy according to Shiji and relevant oracle bones, and their attributed tombs.

$1001=X i a o-Y i($ 小乙) $\rightarrow 1550=\mathrm{Zu}-\mathrm{ji}($ 祖己 $) \rightarrow 1400=\mathrm{Wu}-\mathrm{Ding}($ 武丁 $) \rightarrow 1004$ $=\mathrm{Zu}-$ Geng (祖庚) $\rightarrow 1003=\mathrm{Zu}$-Jia (祖甲) $\rightarrow 1002=$ Geng-Ding (庚丁) $\rightarrow 1500=$ Wu-Yi (武乙) $\rightarrow 1217=$ Wen-Wu-Ding (文武丁) (Figure 5; also see Figures 1 \& 4).

It is widely recognised that the number of late Shang kings coincides with the nine large tombs excavated at the Xibeigang cemetery (e.g. Chang 1980: 110-19, Yang 1986: 52). As previously mentioned, however, the lack of a precise chronology has made it difficult to attribute convincingly each tomb to any particular king. As tomb 84M260 (see Figure 1), which yielded the famous Si-Mu-Wu (司母戊 or 后母戊: Anyang Archaeological Team IA CASS 1987) ding vessel, is most probably the burial place of Bi-Wu (妣戊: Yang \& Yang 1977: 14), the lawful wife of King Wu-Ding, it can be inferred that the king himself was buried in tomb 1400 . Intriguingly, tomb $86 \mathrm{M} 260$ is placed so as to pay respect to (strategy $\mathrm{X})$ the occupant of tomb 1400 (Figure 4d). Further evidence for this attribution comes from the tomb of Fu-Hao (wife of Wu-Ding), in the palace complex at Xiaotun. Her tomb yielded the assemblage that characterises the earliest stage of the Yinxu II phase (IA CASS 1980: 228). Tomb 1001-the inferred tomb of Xiao-Yi-dates to the final stage of the Yinxu I phase, and tomb 1550 dates to the earliest stage of the Yinxu II phase. Tomb 1400 , according to the bronze items excavated from it, dates to the Yinxu II phase (see also the OSM). This evidence indicates that Wu-Ding (probably buried in tomb 1400) organised the funeral ceremonies and buried Kings Xiao-Yi and Zu-Ji. As the Shiji does not 


\section{Koji Mizoguchi \& Junko Uchida}

record the latter's enthronement, it is speculated that he died young while still a prince. The oracle bone scripts, however, record various commemorative rituals routinely performed at his tomb. These observations allow us to attribute tombs 1001 and 1550 to Xiao-Yi and $\mathrm{Zu}-\mathrm{Ji}$, respectively (Figures $4 \mathrm{~b}-\mathrm{d}$ ). This enables the tombs in the reconstructed sequence to be matched to the kings one by one: 1004 ( $\mathrm{Zu}-\mathrm{Geng}) \rightarrow 1003(\mathrm{Zu}-\mathrm{Jia}) \rightarrow 1002$ (GengDing) $\rightarrow 1500$ (Wu-Yi) $\rightarrow 1217$ (Wen-Wu-Ding) (see Figures 4e-i \& 5).

According to the Shiji, Wu-Ding (1400) was the son of Xiao-Yi (1001), and Zu-Ji (1550), $\mathrm{Zu}-\mathrm{Geng}(1004)$ and $\mathrm{Zu}-\mathrm{Jia}(1003)$ were the sons of Wu-Ding. Geng-Ding (1002) was the son of $\mathrm{Zu}$-jia (1003). Wu-Yi (1500) was the son of Geng-Ding, and Wen-Wu-Ding (1217) was the son of Wu-Yi (Figure 5). This shows that Wu-Ding's sons were successively enthroned, effectively making Wu-Ding the founder of a new dynasty. He also founded the Yin capital. This might explain the location of tomb 1400, situated apart from tombs 1001 and 1550 (Figures 1 \& 4d); Wu-Ding himself, or his mourners, intended his spatial location to express his role as dynastic founder, worthy of a distinguished position. This would also explain why tombs 1001, 1550 and 1004 form a cluster (Figures $1 \& 4 \mathrm{e}$ ). The occupant of 1004 (Zu-Geng), and those who buried him, would have attempted to give him equal status to Wu-Ding, by positioning his tomb in a pairing position with 1400 (Figure 4e), while simultaneously placing him as rightful successor to the predecessors of Wu-Ding (i.e. Xiao-Yi in tomb 1001, and Zu-Ji in 1550). Following strategy Z, Zu-Geng and $\mathrm{Zu}$-Jia were buried side by side in tombs 1004 and 1003: a fitting treatment for kingly brothers (Figures 1, 4f \& 5).

Following this, Geng-Ding (tomb 1002), the son of $\mathrm{Zu}$-Jia, was buried via strategy X, paying respect to his uncle, King Zu-Geng (1004) (Figures $1 \& 4 \mathrm{~g}$ ). That he was not buried in a position paying respect to his father suggests that the decision was a highly strategic one and might have related to competition between the faction(s) supporting the line of tombs of 1001, 1550, 1004 and 1002, and the faction(s) supporting the line of 1003, 1500 and 1217.

Geng-Ding's (1002) son Wu-Yi (1500) was buried in a position that effectively received respect from all the previous kings (strategy Y) except Wu-Ding (1400) (Figures $1 \& 4 \mathrm{~h}$ ). This suggests that he or his followers may have attempted to position him highest in the entire genealogical hierarchy represented at the cemetery. Interestingly, from Wu-Yi onwards, unilineal male succession is recorded in Shiji until the end of the dynasty (Figure 5), suggesting that $\mathrm{Wu}-\mathrm{Yi}$ attempted to renew kingly authority and power.

It is interesting to note that Wen-Wu-Ding (tomb 1217), or his faction, chose not only to construct the largest tomb in terms of ramp length, but also to make the main burial pit identical in form to those of tombs 1001 and 1400 - the latter most probably the tomb of Wu-Ding, founder of the late Shang dynasty (Figures 1 \& 4i). Wu-Yi's and Wen-WuDing's reigns were characterised by the revival of old ritual traditions, which Dong Zuo-bin describes as the 'Old School' (Tung 1956) formerly practised by Wu-Ding, also described as "the Wen Wu Ting 'revival' of Wu Ting institutions" (Chang 1980: 187). (It must be noted, however, that this proposal by Dong Zuo-bin is currently under scrutiny.) That this took place immediately before the demise of the Shang dynasty suggests that Wen-Wu-Ding attempted to revitalise power and authority by connecting himself to the founding ancestor, Wu-Ding, in response to the dynastic decline.

(C) Antiquity Publications Ltd, 2018 
Chang (1980: 176, 187-88, 1982: 121-26) hypothesised that 'Ding' and 'Yi', repeatedly used as a part of kings' names, represented two royal descent groups: the Ding (later to become the Zhao in the Zhou period), and the Yi (later to become the $\mathrm{Mu}$ ). Chang assigned four kings to the former group, and seven to the latter, and argued that they coincided with the number of large tombs in the western and eastern zones of the Xibeigang cemetery. The subsequent Zhou system enthroned kings alternately from the Zhao and $\mathrm{Mu}$ groups, and Chang inferred that such a system had already been practised in the Shang period (Chang 1982). Our chronological reconstruction of the Xibeigang cemetery reveals that his model is not sustainable: the tombs were not constructed alternately in the eastern and western zones (Figure 4) (Chang 1982).

Why, then, is there a clear spatial division between these zones? Before the construction of the first royal tomb (1001) in the western zone, tombs 1443 and 50WGM1 (probably belonging to the Middle Shang kings residing at Huanbei Shangcheng 洹北商城; Tang 1999) had already been built in the eastern zone. The eastern zone was hence already designated as the ancestral burial ground, and became a location for rituals as indicated by the continuous sequence of sacrificial pits and burials. Wu-Ding, who probably organised the mortuary rituals of Xiao-Yi (tomb 1001) and Zu-Ji (tomb 1550), and was effectively the head of a new dynasty, founded the new burial ground in the western zone. When Wu-Ding died, he was commemorated as both the founder of the new dynasty and as the legitimate successor of the Middle Shang kings; his burial, in the eastern zone, also sought to glorify the ancestors. The tombs of Wu-Ding's sons and their successors, by contrast, were placed in the western zone that Wu-Ding had designated as the new royal burial ground, while ancestor rituals continued to be conducted in the eastern zone. Ultimately, we find it significant that the results of archaeological investigation coincide with those of expert analysis of the historical records.

\section{Concluding remarks}

The detailed chronological reconstruction of the Xibeigang cemetery has allowed us to recreate the strategic decisions of the mourners who constructed the royal tombs and left material traces of funeral ceremonies. The richness of the late Shang archaeological record includes sophisticated bronze ritual vessels and large urban settlements, as well as the royal tombs of Xibeigang, and offers important material for comparison with other early civilisations, including those of Egypt, Mesopotamia and the Indus (e.g. Trigger 2003). That very richness allows us to study the social organisation and institutions of the Shang in detail, and offers detailed insight into the social practices of individuals and groups of varying membership at various scales. A number of case studies have demonstrated that our understanding of the organisational characteristics of a society can be significantly improved by examining how individuals and groups pursued the social practices that contributed to the maintenance and transformation of its institutions (e.g. von Falkenhausen 2006). The present study has applied this approach to the archaeology of the Shang period, thereby illuminating the ways in which the Shang ruling class organised themselves, competed with one another and attempted to maintain and enhance their power and authority. 


\section{Acknowledgements}

We thank Gina Barnes and Lothar von Falkenhausen for their extensive, insightful and encouraging comments. We also wish to thank Yu-yun Lin and Zhi-hua Xie for allowing us to study and make detailed notes and sketches of the artefacts used for the chronological reformulation undertaken in this paper. This work was supported by JSPS KAKENHI grant JP17K03211.

\section{Supplementary material}

To view supplementary material for this article, please visit https://doi.org/10.15184/aqy. 2018.19

\section{References}

Anonymous. 1977. Anyang Yin-xu Wu-haomu zuodan jiyao [Tomb no. 5 of Anyang Yixu]. Kaogu 1977: 341-50.

Anyang Archaeological Team IA CASS. 1987. Yin-xu 259, 260 hao mu Fajue Baogao [The excavation of tombs M259 and M260 at the Yin ruins]. Kaogu xuebao 1987: 99-117.

Barnes, G.L. 2015. Archaeology of East Asia: the rise of civilization in China, Korea and Japan. Oxford: Oxbow.

Brumfiel, E. \& J.W. Fox (ed.). 2003. Factional competition and political development in the New World. Cambridge: Cambridge University Press.

Chang, K.C. 1977. The archaeology of ancient China. London: Yale University Press.

- 1980. Shang civilization. London: Yale University Press.

- 1982. Zhong-guo Qing-tong Shi-dai [The Bronze Age of China]. Hong Kong: Chinese University of Hong Kong.

Falkenhausen, L. von. 2006. Chinese society in the age of Confucius: the archaeological evidence. Los Angeles (CA): Cotsen Institute of Archaeology Press.

Giddens, A. 1984. The constitution of society: outline of the theory of structuration. Cambridge: Polity.

IA CASS (Institute of Archaeology, Chinese Academy of Social Sciences). 1980. Yin-xu Fu-Hao mu [Tomb of Lady Hao at Yin-xu in An-Yang]. Beijing: Cultural Relics.

- 1994. Yin-xu de Fa-xian yu Yan-jiu [Archaeology, excavation and researches in the Yin ruins]. Beijing: Science.

Kane, V. 1975. A re-examination of Anyang archaeology. Ars Orientalis 10: 103, 106, 108-10.

Keighteey, D. 1999. The Shang: China's first historical dynasty, in M. Loewe \& E. Shaughnessy (ed.) The Cambridge history of ancient China: from the origins of civilization to 221 B.C.: 232-91. Cambridge: Cambridge University Press. https://doi.org/10.1017/CHOL9780521470308.006
LI, C. 1959. Ji Xing balei ji qi wenshi zhi yanbian [Typological changes of designs of eight types of hairpins]. Bulletin of the Institute of History and Philology Academia Sinica 30: 1-69.

Liang, S. \& Q. GaO. 1962. Houjiazhuang (Henan Anyang Houjiazhuang Yin dai mudi) di er ben, 1001 hao da mu. Taipei: Academia Sinica.

- 1965. Houjiazhuang (Henan Anyang Houjiazhuang Yin dai mudi) di san ben, 1002 hao da mu. Taipei: Academia Sinica.

- 1967. Houjiazhuang (Henan Anyang Houjiazhuang Yin dai mudi) di si ben, 1003 hao da mu. Taipei: Academia Sinica.

- 1968. Houjiazhuang (Henan Anyang Houjiazhuang Yin dai mudi) di liu ben, 1217 hao da mu. Taipei: Academia Sinica.

- 1970. Houjiazhuang (Henan Anyang Houjiazhuang Yin dai mudi) di wu ben, 1004 hao da mu. Taipei: Academia Sinica.

- 1974. Houjiazhuang (Henan Anyang Houjiazhuang Yin dai mudi) di qi ben, 1500 hao da mu. Taipei: Academia Sinica.

- 1976. Houjiazhuang (Henan Anyang Houjiazhuang Yin dai mudi) di ba ben, 1550 hao da mu. Taipei: Academia Sinica.

- 1996. Houjiazhuang (Henan Anyang Houjiazhuang Yin dai mudi) di jiu ben, 1129, 1400, 1443 hao da $m u$. Taipei: Academia Sinica.

Mizoguchi, K. 1993. Time in the reproduction of mortuary practices. World Archaeology 25: 223-35. https://doi.org/10.1080/00438243.1993.9980239

- 2005. Genealogy in the ground: observations of jar burials of the Yayoi period, northern Kyushu, Japan. Antiquity 79: 316-26. https://doi.org/10.1017/S0003598X00114115

- 2013. The archaeology of Japan: from the earliest rice farming villages to the rise of the state. Cambridge: Cambridge University Press.

- 2014. The centre of their life-world: the archaeology of experience at the Middle Yayoi cemetery of Tateiwa-Hotta, Japan. Antiquity 88: 836-50. https://doi.org/10.1017/S0003598X00050729

(C) Antiquity Publications Ltd, 2018 


\section{The Anyang Xibeigang Shang royal tombs revisited}

- 2015. De-paradoxisation of paradoxes by referring to death as an ultimate paradox: the case of the state-formation phase of Japan, in C. Renfrew, M.J. Boyd \& I. Morley (ed.) Death rituals, social order and the archaeology of immortality in the ancient world: 255-79. Cambridge: Cambridge University Press.

Namba [Uсhida], J. 1990. Inkyo zenhan-ki no seido-ki no ryuha to hen'nen [The typo-chronology of bronze vessels of the early Yin-xu period of Shang China and their traditions]. Shirin 73(6): 1-43.

- 1995a. Inkyo shutsudo no iwayuru kosshi ni tsuite [On the Gu-si bone spatulas excavated from Anyang Yin-xu 1]. Kodai-bunka (Cultura Antiqua) 47(9): 25-36.

- 1995b. Inkyo shutsudo no iwayuru kosshi ni tsuite [On the Gu-si bone spatulas excavated from Anyang Yin-xu 2]. Kodai-bunka (Cultura Antiqua) 47(12): 40-46.

Parker Pearson, M. 1999. The archaeology of death and burial. Stroud: Sutton.

TANG, J. 1999. Zhong-Shang Wen-hua Yan-Jiu [A study of mid Shang culture]. Kaogu 1999: 393-420.

Tilley, C. (ed.). 1994. Interpretative archaeology. Oxford: Berg.

TRIGger, B. 2003. Understanding early civilizations. Cambridge: Cambridge University Press. https://doi.org/10.1017/CBO9780511840630

Tung, T. 1956. Bokuji no jikikubun [Chronology of divination on oracle bones], in Y. Kawade (ed.) Teihon Shodo Zenshu [Complete works of calligraphy volume 1]: 141-51. Tokyo: Kawade Shobo.
Umehara, S. 1940. Ka-nan-Anyou-ihou [Selected ancient treasures found at Anyang, Yin sites]. Kyoto: Kobayashi-Shashin-insatsusho.

Xia Shang Zhou Chronology Project Team. 2000. Xia Shang Zhou Duandai Gongcheng 1996-2000 Nian Jieduan Chengguo Baogao [The report of the dating project of the Xia, Shang and Zhou periods for the period between 1996 and 2000]. Beijing: Shijie Tushu.

YANG, H. 1986. The Shang dynasty cemetery system, in K.C. Chang (ed.) Studies of Shang archaeology: selected papers from the international conference of the Shang civilisation: 49-63. London: Yale University Press.

Yang, X. 1981. Anyang Yin-xu Xibeigang Da-mu de Fen-qi ji youguan wenti [The chronology and some other issues concerning the Anyang Yin-xu Xibeigang royal tombs]. Zhong-yuan wen-wu 1981(3): 47-52.

- 1991. Yin-xu de Nian dai ji xing-zhi wen-ti [Issue concerning the dating and the character of Yin-xu]. Zhong-yuan wen-wu 1991(1): 49-58.

Yang, X. \& B. Yang. 1977. Cong Shangdai Jisi keng kan Shangdai nuli shehui de Rensheng [The human sacrifices of the Shang slave society viewed in the light of the sacrificial pits of the Shang Dynasty]. Kaogu 1977(1): 14.

Yoffee, N. 2005. Myths of the archaic state: evolution of the earliest cities, states, and civilizations. Cambridge: Cambridge University Press. https://doi.org/10.1017/CBO9780511489662 